\title{
Таллиевая минерализация на Оленинском золоторудном проявлении, пояс Колмозеро-Воронья
}

\author{
Калинин А.А., Савченко Е.Э. \\ Геологический институт КНЦ РАН, Anamumbl, kalinin@geoksc.apatity.ru
}

Аннотация. Таллиевая минерализация установлена в кварцевых метасоматитах, образующих эллипсоидальной формы обособления среди турмалин-мусковит-кварцевых сланцев. Изучен химический состав золота и серебра, молибденита и таллиевых фаз - сульфидов и арсенатов - в кварцевых метасоматитах. Молибденит отличается высоким содержанием селена и рения. Таллий установлен в дисульфидизированном пирротине (до 32 мас. \%), в халькопирите на границе с пиритом, в самородном золоте, в гессите, в сульфидах серебра и железа, а также в кислородсодержащих фазах (арсенатах), по составу близких к таллиумфармакосидериту. Примесь таллия в самородном золоте отмечена впервые. Таллийсодержащие сульфиды и арсенаты развиваются по самородному золоту, арсенопириту, пириту в виде кайм мощностью в несколько микрометров.

Ключевые слова: пояс Колмозеро-Воронья, Оленинское рудопроявление, золото, серебро, молибденит, таллий, таллиумфармакосидерит.

\section{Thallium mineralization in the Oleninskoe gold prospect, Kolmozero-Voronya belt}

\author{
Kalinin A.A., Savchenko Ye.E. \\ Geological institute KSC RAS, Apatity,kalinin@geoksc.apatity.ru
}

\begin{abstract}
Mineralization of thallium was found in quartz metasomatic rocks, which form ellipsoid bodies in quartz-muscovite-tourmaline schists. Chemical composition of native gold (electrum), molybdenite, and thallium sulfides and arsenates was studied. The molybdenite is rich in Se and Re. Thallium was found in marcasite (up to $32 \%$ ), in chalcopyrite at the boundary with pyrite, in native gold (the first finding in the world), in hessite, in sulfides of $\mathrm{Ag}$ and $\mathrm{Fe}$, and in arsenates, close to thalliumpharmacosiderite. Tl-bearing mineral phases develop as rims in grains of electrum, arsenopyrite, and, rarely, pyrite.
\end{abstract}

Key words: Kolmozero-Voronya belt, Oleninskoe occurrence, gold, silver, molybdenite, thallium, thalliumpharmacosiderite.

Оленинское рудопроявление золота расположено в северо-западной части пояса КолмозероВоронья вблизи узла пересечения тектонических нарушений северо-западного простирания, ограничивающих толщу амфиболитов хр. Оленьего, с крупным субмеридиональным разломом ГрибноеЛешая. Особенности геологического строения рудопроявления Оленинское рассмотрены в работах (Волков, Новиков, 2002, Галкин, 2006, Калинин и др., 2010 и др.). Рудопроявление приурочено к толще амфиболитов хр. Оленьего, среди которых отмечаются согласные простиранию толщи тела метапироксенитов и метаперидотитов. С южной стороны толща амфиболитов граничит с андалузит-биотитовыми плагиогнейсами поросозерской серии, с севера - с толщей переслаивания амфиболитов и кордиерит-биотитовых, андалузит-биотитовых, частью с гранатом и ставролитом плагиогнейсов и сланцев. Геологическая структура рудопроявления существенно осложнена согласными телами (дайками) гранит-порфиров, вмещающими породами для которых служат как амфиболиты, так и глиноземистые сланцы, мощность даек от 0.1 до 5-6 метров.

Минерализация золота на рудопроявлении контролируются зонами кислотного выщелачивания амфиболитов хр. Оленьего и гранит-порфиров. Золоторудная зона представляет собой серию сближенных линзовидных тел на площади 300×50 м. Ориентировка рудной зоны в пространстве в целом соответствует общему директивному северо-западному простиранию пояса КолмозероВоронья. Зоны минерализованных кварцевых, турмалин-кварцевых и турмалин-мусковиткварцевых метасоматитов по отношению к вмещающим амфиболитам занимают секущее положе- 
ние под острым углом 5-10 градусов и образуют систему из трех эшелонированных линз. Мощность выходящих на поверхность линзовидных рудных тел 1.8-3.5 м при протяженности до 50 м.

Строение средней из трех линз зональное: ее центральная зона сложена турмалин-мусковиткварцевыми сланцами-метасоматитами, форма этой зоны сложная - с раздувами до 1 м и пережимами до 5 см. Кварцевые метасоматиты развиваются в виде прерывистой зоны мощностью до 10 см по контакту мусковит-кварцевых метасоматитов с вмещающими амфиболитами. Внешняя зона сложена биотитизированными амфиболитами, мощность зоны интенсивной биотитизации до $20 \mathrm{~cm}$. Для всех измененных пород характерна пирротин-арсенопиритовая минерализация с золотом, а богатая сурьмяно-серебряная минерализация, описанная нами ранее (Калинин и др., 2017), приурочена к маломощной и прерывистой зоне кварцевых метасоматитов. Для турмалин-мусковит-кварцевых метасоматитов характерно содержание золота 1-3 г/т и выше, а в кварцевых метасоматитах повышается до более 80 г/т.

Среди турмалин-мусковит-кварцевых метасоматитов отмечены эллипсоидальной формы обособления кварца размером до 30 см по длинной оси и до 20 см по малой оси, обтекаемые сланцеватостью вмещающих сланцев. В отличие от зоны кварцевых метасоматитов, кварц в таких желваках не тонкозернистый, а среднезернистый до крупнозернистого, темно-серый до черного, полупрозрачный. Кроме кварца в составе породы отмечены альбит, турмалин и рудные минералы, но они вместе составляют менее 10 \% объема породы.

Эти кварцевые обособления отличаются от турмалин-мусковит-кварцевых, турмалинкварцевых и кварцевых метасоматитов по своим геохимическим характеристикам и по составу рудной минерализации. Содержание свинца и сурьмы (а также висмута) здесь низкое, соответственно, отсутствуют минералы группы сульфосолей. Кроме того, содержание практически всех литофильных и сидерофильных металлов существенно ниже, чем во вмещающих породах, но повышено содержание золота, серебра, теллура, хрома и молибдена.

Состав рудной минерализации изучался в аншлифах - приполированных сколках образцов и в искусственных аншлифах, изготовленных из концентратов тяжелой немагнитной фракции после деления проб в жидкости Клеричи (АК-711) или бромоформе (АК-710).

Основные минералы в составе рудной минерализации описываемых кварцевых обособлений - арсенопирит, пирит, пирротин, второстепенные - халькопирит, сфалерит, золото (электрум), гессит, молибденит, ютенбогардтит, акантит, редкие - кервеллеит, калаверит, петцит, ковеллин, гудмундит, ауростибит, леллингит, пентландит, самородные мышьяк и висмут. Из минералов класса оксидов установлены магнетит, ильменит, рутил, ганит. Выделения рудных минералов тяготеют к зернам силикатных минералов - альбита и турмалина, в которых образуют тонкую обильную вкрапленность, реже развиваются в межзерновом пространстве кварца.

Принципиально важным отличием минерализации кварцевых обособлений является относительно широкое развитие пирита, отсутствующего в других породах рудопроявления. Появление пирита свидетельствует о снижении температуры рудообразования по сравнению с вмещающими породами и/или о повышении активности серы.

Для электрума (20 проанализированных на САМЕСА зерен) по содержанию золота выделяется три частотных максимума: 35-36 мас. \%, 43-53 мас. \% и 59-66 мас. \%. Многие выделения электрума неоднородны, их внешние зоны обогащены серебром по сравнению с центральными.

Молибденит по составу отличается от молибденита расположенного неподалеку медномолибденового рудопроявления Пеллапахк (Белолипецкий и др., 1987) весьма высоким содержанием селена 6-12 мас. \% и наличием примеси Re до 0.35 мас. \% (табл. 1). Молибденит с такими же особенностями химического состава был описан нами ранее на Озерном рудопроявлении пояса Салла-Куолаярви (Калинин и др., 2013).

Отличительной особенностью рудной минерализации в рассматриваемых кварцевых обособлениях является присутствие таллийсодержащих фаз. Стоит подчеркнуть, что таллиевые фазы отмечены не только в той пробе, которая делилась в жидкости Клеричи (эта жидкость представляет собой водный раствор, содержащий равные доли формиата и малоната таллия), но и в другой, де- 
лившейся в бромоформе, поэтому нельзя говорить о развитии таллиевых фаз в результате реакции минералов с жидкостью Клеричи.

Таблица 1. Состав молибденита (MS-46 CAMECA, мас. \%) рудопроявлений Оленинское, Пеллапахк и Озерное.

Table 1. Composition of molybdenite from the Oleninskoe, Pellapahk, and Ozernoe prospects, wt. \%.

\begin{tabular}{|c|l|l|l|l|l|l|l|}
\hline & \multicolumn{3}{|c|}{ Оленинское } & \multicolumn{2}{c|}{ Пеллапахк } & \multicolumn{2}{c|}{ Озерное } \\
\hline $\mathrm{Fe}$ & 0.03 & 0.00 & 0.00 & 0.05 & 0.00 & 0.00 & 0.08 \\
\hline $\mathrm{Ni}$ & 0.04 & 0.00 & 0.00 & 0.00 & 0.00 & 0.00 & 0.00 \\
\hline $\mathrm{Mo}$ & 56.17 & 55.21 & 57.47 & 60.25 & 60.25 & 55.91 & 55.48 \\
\hline $\mathrm{Pb}$ & 0.00 & 0.00 & 0.00 & 0.00 & 0.00 & 0.00 & 0.00 \\
\hline $\mathrm{Re}$ & 0.35 & 0.00 & 0.00 & 0.00 & 0.00 & 0.32 & 0.14 \\
\hline $\mathrm{S}$ & 35.48 & 31.91 & 36.17 & 39.74 & 39.19 & 32.08 & 37.95 \\
\hline $\mathrm{Se}$ & 6.90 & 12.65 & 6.66 & 0.00 & 0.03 & 12.12 & 6.42 \\
\hline $\mathrm{Te}$ & 0.00 & 0.00 & 0.00 & 0.00 & 0.00 & 0.00 & 0.00 \\
\hline $\mathrm{Cумма}$ & 98.98 & 99.78 & 100.30 & 100.05 & 99.47 & 100.44 & 100.07 \\
\hline \multicolumn{7}{|c|}{ Коэффициенты кристаллохимической формулы } \\
\hline $\mathrm{Fe}$ & 0.00 & 0.00 & 0.00 & 0.00 & 0.00 & 0.00 & 0.00 \\
\hline $\mathrm{Ni}$ & 0.00 & 0.00 & 0.00 & 0.00 & 0.00 & 0.00 & 0.00 \\
\hline $\mathrm{Mo}$ & 0.98 & 1.00 & 0.99 & 1.01 & 1.03 & 1.01 & 0.91 \\
\hline $\mathrm{Pb}$ & 0.00 & 0.00 & 0.00 & 0.00 & 0.00 & 0.00 & 0.00 \\
\hline $\mathrm{Re}$ & 0.00 & 0.00 & 0.00 & 0.00 & 0.00 & 0.00 & 0.00 \\
\hline $\mathrm{S}$ & 1.85 & 1.72 & 1.86 & 2.00 & 2.00 & 1.73 & 1.87 \\
\hline $\mathrm{Se}$ & 0.15 & 0.28 & 0.14 & 0.000 & 0.00 & 0.27 & 0.13 \\
\hline $\mathrm{Te}$ & 0.00 & 0.00 & 0.00 & 0.00 & 0.00 & 0.00 & 0.00 \\
\hline
\end{tabular}

Геохимия и минералогия таллия изучены сравнительно слабо. Таллий относится к рассеянным элементам и добывается не из собственных минералов, а из сульфидных концентратов, чаще всего как побочный продукт переработки свинцово-цинковых и медных руд, где содержание таллия находится на уровне нескольких граммов на тонну. Собственные минералы таллия (их около 30)
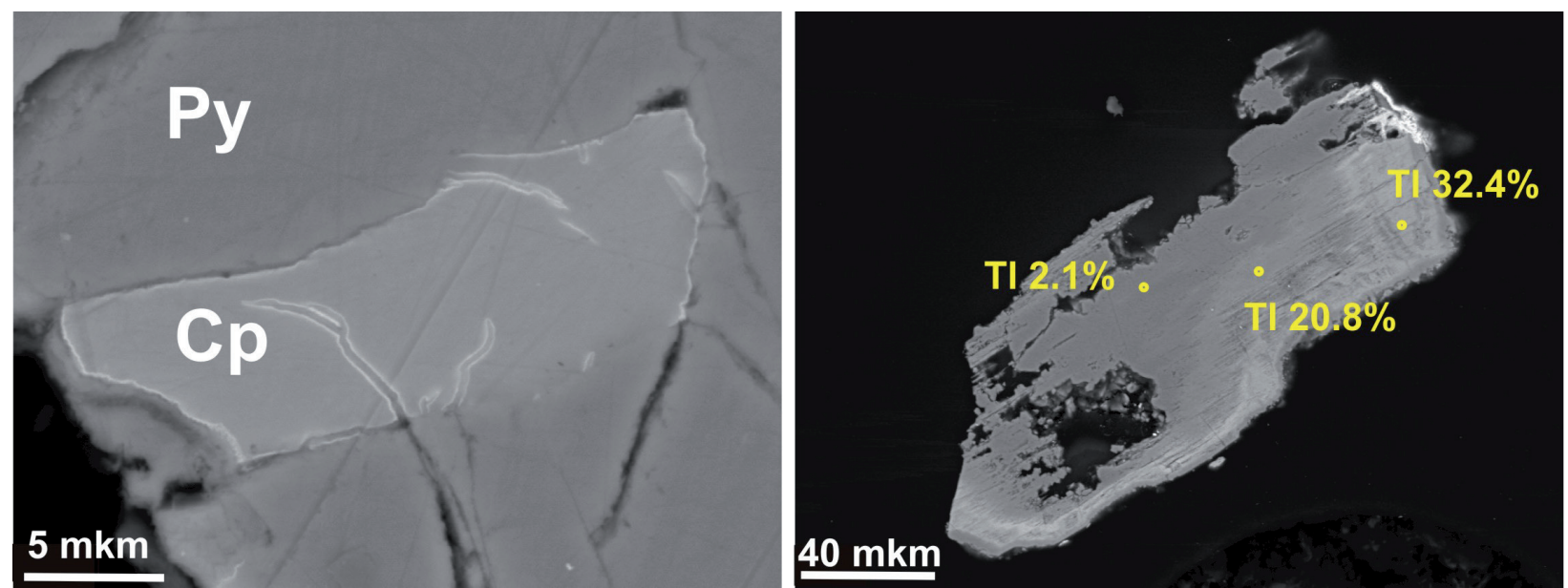

Рис. 1. Слева - развитие таллиевой фазы по границе включения халькопирита в пирите, справа - зерно таллийсодержащего дисульфидизированного пирротина с зональными распределением примеси, BSE-фото. Ру - пирит, Сp - халькопирит.

Fig. 1. Thallium-bearing phase at the boundary of chalcopyrite and pyrite (on the left) and Tl-bearing grain of disulfidized pyrrhotite with zonal distribution of the trace element, BSE-image. Py - pyrite, $\mathrm{Cp}$ - chalcopyrite (on the right). 
Таблица 2. Состав таллийсодержащих фаз рудопроявления Оленинского.

Table 2. Composition of Tl-bearing mineral phases from the Oleninskoe prospect.

\begin{tabular}{|c|c|c|c|c|c|c|c|c|c|c|c|c|c|}
\hline \multirow[b]{2}{*}{$\mathrm{Fe}$} & \multicolumn{2}{|c|}{ Золото } & \multirow{2}{*}{ 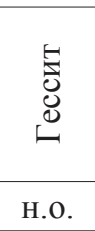 } & \multirow{2}{*}{ 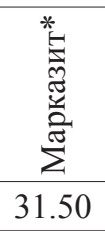 } & \multicolumn{5}{|c|}{ Фаза «А» } & \multicolumn{3}{|c|}{ Фаза «B» } & \multirow{2}{*}{$\begin{array}{c}\hat{\hat{\vartheta}} \\
\widetilde{\Xi} \\
\tilde{\tilde{\Xi}} \\
\theta \\
0.35\end{array}$} \\
\hline & 2.12 & 2.91 & & & 0.63 & 0.89 & 0.65 & H.O. & 1.24 & 20.28 & 12.89 & 8.60 & \\
\hline $\mathrm{Ni}$ & H.o. & H.O. & H.O. & 0.20 & H.O. & H.O. & H.O. & H.O. & H.O. & H.O. & H.O. & H.O. & H.о. \\
\hline $\mathrm{Cu}$ & H.O. & H.O. & H.O. & H.о. & H.O. & H.O. & H.O. & 7.48 & H.O. & 2.06 & H.O. & H.O. & H.O. \\
\hline $\mathrm{Ag}$ & 17.16 & 14.86 & 58.05 & H.O. & 37.71 & 29.30 & 55.66 & 52.39 & 40.11 & 29.94 & 33.18 & 20.75 & 60.68 \\
\hline $\mathrm{Au}$ & 74.73 & 74.36 & 2.58 & H.O. & 42.25 & 38.36 & 30.05 & 7.21 & 46.00 & H.O. & 16.50 & 40.17 & 21.11 \\
\hline $\mathrm{Hg}$ & H.o. & H.o. & H.o. & H.о. & H.o. & H.о. & H.о. & H.o. & H.о. & H.o. & H.о. & 3.07 & H.о. \\
\hline $\mathrm{Tl}$ & 5.34 & 6.95 & 3.06 & 32.37 & 8.10 & 22.56 & 3.63 & 19.43 & 3.71 & 32.15 & 22.88 & 18.45 & 2.99 \\
\hline $\mathrm{Al}$ & H.о. & 0.11 & H.о. & H.о. & H.о. & H.O. & H.o. & H.о. & H.о. & H.о. & H.о. & H.о. & H.о. \\
\hline As & 0.66 & 0.80 & H.O. & H.O. & 1.31 & 0.19 & H.O. & H.O. & 1.26 & 0.17 & 0.24 & H.O. & 0.37 \\
\hline $\mathrm{S}$ & H.O. & H.O. & H.O. & 34.98 & 10.96 & 8.71 & 10.00 & 11.02 & 7.68 & 15.41 & 14.32 & 8.96 & 14.50 \\
\hline $\mathrm{Se}$ & H.O. & H.O. & H.O. & H.O. & H.O. & H.O. & H.O. & 2.47 & H.O. & H.O. & H.O. & H.O. & H.O. \\
\hline $\mathrm{Te}$ & H.o. & H.o. & 36.31 & H.o. & H.о. & H.o. & H.o. & H.o. & H.o. & H.o. & H.о. & H.O. & H.O. \\
\hline Сумма & 100 & 100 & 100 & 100 & 100 & 100 & 100 & 100 & 100 & 100 & 100 & 100 & 100 \\
\hline
\end{tabular}

Коэффициенты кристаллохимической формулы

\begin{tabular}{|c|c|c|c|c|c|c|c|c|c|c|c|c|c|}
\hline $\mathrm{Fe}$ & 0.06 & 0.09 & - & 1.03 & 0.03 & 0.06 & 0.04 & - & 0.09 & 0.75 & 0.51 & 0.55 & 0.01 \\
\hline $\mathrm{Ni}$ & - & - & - & 0.01 & - & - & - & - & - & - & - & - & - \\
\hline $\mathrm{Cu}$ & - & - & - & - & - & - & - & 0.31 & - & 0.07 & - & - & - \\
\hline $\mathrm{Ag}$ & 0.26 & 0.22 & 1.89 & - & 1.01 & 0.99 & 1.66 & 1.29 & 1.45 & 0.58 & 0.684 & 0.69 & 1.23 \\
\hline $\mathrm{Au}$ & 0.62 & 0.61 & 0.05 & - & 0.62 & 0.71 & 0.49 & 0.10 & 0.91 & - & 0.19 & 0.73 & 0.23 \\
\hline $\mathrm{Hg}$ & - & - & - & - & - & - & - & - & - & - & - & 0.06 & - \\
\hline $\mathrm{Tl}$ & 0.04 & 0.06 & 0.05 & 0.29 & 0.11 & 0.40 & 0.06 & 0.25 & 0.07 & 0.33 & 0.25 & 0.32 & 0.03 \\
\hline $\mathrm{Al}$ & - & 0.01 & - & - & - & - & - & - & - & - & - & - & - \\
\hline$\Sigma$ кат. & - & - & 1.99 & 1.33 & 1.77 & 2.16 & 2.24 & 1.96 & 2.52 & 1.72 & 1.63 & 2.35 & 1.51 \\
\hline $\mathrm{As}$ & 0.01 & 0.02 & - & 0.03 & 0.01 & 0.01 & - & - & 0.07 & 0.01 & 0.01 & - & 0.01 \\
\hline $\mathrm{S}$ & - & - & - & 1.97 & 0.99 & 0.99 & 1.00 & 0.92 & 0.93 & 0.99 & 0.99 & 1.00 & 0.99 \\
\hline $\mathrm{Se}$ & - & - & - & - & - & - & - & 0.08 & - & - & - & - & - \\
\hline $\mathrm{Te}$ & - & - & 1.00 & - & - & - & - & - & - & - & - & - & - \\
\hline
\end{tabular}

Примечание: оценка составов выполнена на энергодисперсионной приставке Bruker X Flash-5010, состав золота - на MS-46 CAMECA; н.о. - элемент не определялся.

представлены преимущественно сложными сульфидами (c Fe, $\mathrm{Pb}, \mathrm{As}, \mathrm{Sb})$ и их аналогами, известны также галогениды таллия, сульфаты и арсенаты. В Кольском регионе ранее были описаны только фазы таллия и палладия в Федорово-Панском расслоенном комплексе (Грошев и др., 2012).

На Оленинском рудопроявлении таллий установлен (табл. 2) в марказите (дисульфидизированном пирротине) (от 2 до 32 мас. \%, рис. 1), в халькопирите на границе с пиритом (рис. 1), в самородном золоте (рис. 2), в гессите (около 2 мас. \%), в сульфидах серебра и железа (возможно, среди них есть новые минеральные фазы), а также в кислородсодержащих фазах - арсенатах, по составу близких к таллиумфармакосидериту.

В одном из зерен золота размером около 0.2 мм установлена примесь таллия 5-6 мас. \%. Ранее в мировой литературе примесь таллия в золоте не отмечалась. Зерно с примесью таллия имеет необычный красноватый оттенок и визуально похоже на самородную медь. Кроме таллия в этом золоте есть примеси железа около 2 мас. \%, мышьяка, меди и сурьмы на уровне десятых долей \% (табл. 2). 

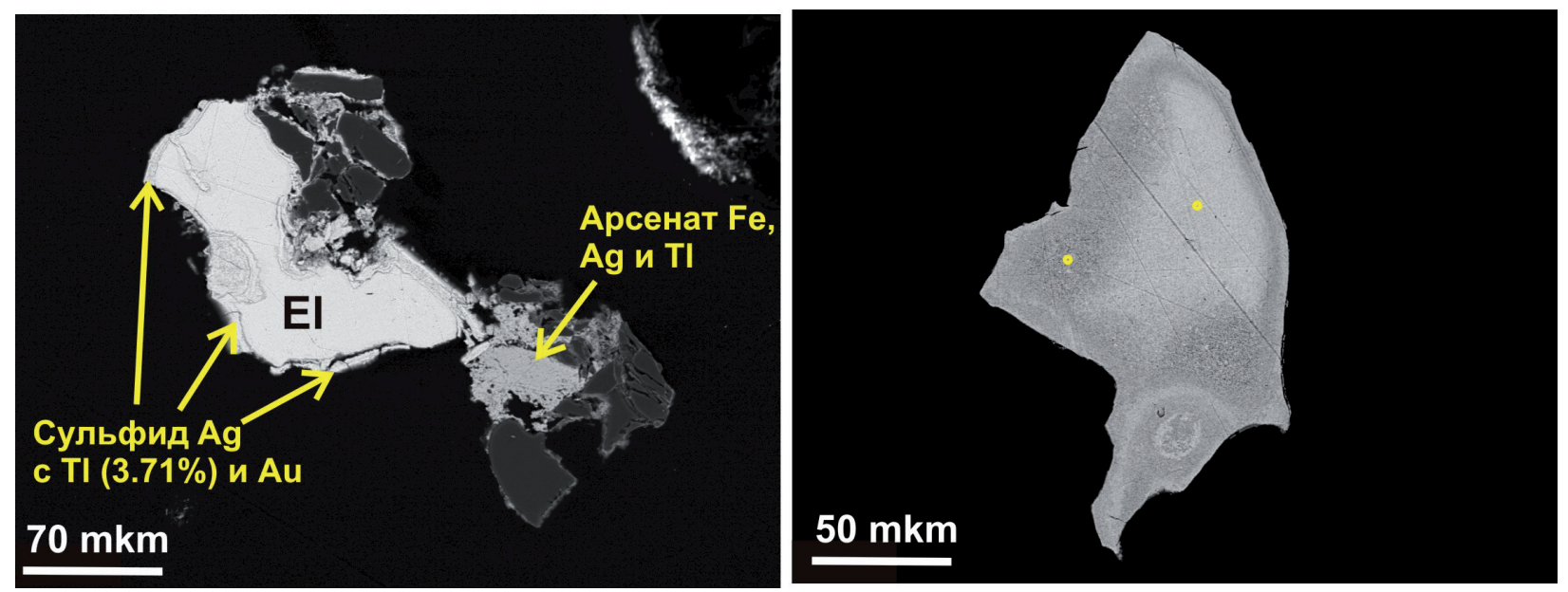

Рис. 2. Слева - развитие таллийсодержащего сульфида серебра и арсената Fe, Ag и Tl по электруму (El); справа - золото с примесью таллия (помечены точки анализа), BSE-фото.

Fig. 2. Tl-bearing sulfide and arsenate of $\mathrm{Fe}, \mathrm{Ag}$, and $\mathrm{Tl}$ as a rim of electrum (El) grain (on the left) and a grain of gold with the trace $\mathrm{Tl}$ (on the right, points of analyses are marked), BSE-image.

В виде кайм мощностью в первые микроны по зернам электрума, реже по арсенопириту и пириту, развиваются сульфиды серебра и железа с таллием и арсенаты железа и таллия. Сульфиды по соотношению металлов и серы близки к акантиту $\operatorname{Ag}_{2} \mathrm{~S}$ (табл. 2), но в группу катионов, кроме серебра, входят также таллий, золото, железо, медь. По аналогии с акантитом в значительной мере условно составы таллийсодержащих сульфидных фаз рассчитаны на сумму анионов, равную 1.

Зарегистрированный как минеральный вид водный арсенат железа и таллия носит название таллиумфармакосидерит $\mathrm{TlFe}_{4}\left[\left(\mathrm{AsO}_{4}\right)_{3}(\mathrm{OH})_{4}\right] \cdot 4 \mathrm{H}_{2} \mathrm{O}$. Фаза, близкая по составу к таллиумфармакосидериту, установлена нами на Оленинском рудопроявлении. Кроме того, отмечена неизвестная фаза с высоким содержанием серебра (выше 30 мас. \%) (рис. 2). В составе этой фазы установлены (CAMECA MS-46, масс. \%): $\mathrm{Fe}_{2} \mathrm{O}_{3} 10.15, \mathrm{Tl}_{2} \mathrm{O} 30.32, \mathrm{Ag}_{2} \mathrm{O} 33.99, \mathrm{As}_{2} \mathrm{O}_{5}$ 13.97, а также примеси Sb и $\mathrm{Au}$ на уровне $0.2 \%$, сумма 88.93. Эта фаза может представить собой новый минеральный вид.

\section{Литература}

1. Белолипецкий А.П., Калинин А.А., Петров С.И. Минералогия и геохимия метасоматитов зон глубинных разломов. Апатиты: Изд-во КФАН СССР. 1987. 115 С.

2. Волков А.В., Новиков И.А. Золото-сульфидное месторождение Оленинское (Кольский п-ов, Россия) // Геология рудных месторождений. 2002. Т. 44. № 5. С. 412-424.

3. Галкин Н.Н. Геология и минералогия золоторудных проявлений Пеллапахк-Оленинского рудного узла. Кольский полуостров. Автореф. дис. ... канд. геол.-мин. наук. Апатиты. 2006. 22 С.

4. Грошев Н.Ю., Волошин А.В., Субботин В.В., Савченко Е.Э. Pd2Tl и Pd3Tl - новые интерметаллы в Фёдорово-Панском расслоенном комплексе. Труды IX Всероссийской (с международным участием) Ферсмановской научной сессии, посвящённой 60-летию Геологического института КНЦ РАН. Апатиты, 2-3 апреля 2012 г. С. $238-241$.

5. Калинин А.А., Кудряшов Н.М., Галкин Н.Н. Рудопроявления золота, меди и молибдена в зеленокаменном поясе Колмозеро-Воронья (Кольский полуостров): геологические особенности и возраст / Золото Кольского полуострова и сопредельных территорий. Апатиты. К\&М. 2010. С. 51-59.

6. Калинин А.А., Савченко Е.Э., Селиванова Е.А. Рений- и селенсодержащий молибденит рудопроявления Озерное в Салла-Куолаярвинской зоне, Северная Карелия // Записки РМО. 2013. №6. С. 105-115.

7. Калинин А.А., Савченко Е.Э., Селиванова Е.А.. Минералы благородных металлов в Оленинском рудопроявлении золота, пояс Колмозеро-Воронья (Кольский полуостров) // Записки РМО. 2017. № 1. С. $43-58$. 